\title{
Mission Unaccomplished: Beyond "Talk[ing] a Good Game" to Promote Diversity and Inclusion
}

Tara Lehan, $\mathrm{PhD}$

Northcentral University, San Diego, California, United States

(iD https://orcid.org/0000-0001-9041-0553

Heather Hussey, PhD

Northcentral University, San Diego, California, United States

https://orcid.org/0000-0002-7237-7929

Ashley Babcock, EdD

Northcentral University, San Diego, California, United States

(iD) https://orcid.org/0000-0002-3371-1912

Contact: tlehan@ncu.edu

\section{Abstract}

Guided by feminist standpoint theory and scholars' calls to move beyond merely counting individuals to understand the extent to which higher education institutions are diverse, the authors invited faculty members, staff members, and administrators from minoritized groups to describe their perceptions and experiences, including those associated with diversity and inclusion efforts at their institutions. In association with various dynamics, these individuals frequently described such initiatives as mostly talk with little to no meaningful objectives and outcomes. Based on these findings, we provide a three-step process that can be followed to disrupt and dismantle systems of (dis)advantage to promote greater diversity and inclusion.

Keywords: diversity; inclusion; initiative; higher education

Date Submitted: March 13, 2020 | Date Published: July 9, 2020

\section{Recommended Citation}

Lehan, T., Hussey, H. \& Babcock, A. (2020). Mission unaccomplished: Beyond "talk[ing] a good game" to promote diversity and inclusion. Journal of Educational Research and Practice, 10, 167-184.

https://doi.org/10.5590/JERAP.2020.10.1.12

\section{Introduction}

Life in higher education has been likened to participation in a competitive game (Lemon, 2018). There are rules, both overt and covert, by which everyone must play or risk facing a penalty or even ejection. Further, there are clear winners and losers, as evidenced by who tends to remain in the game and advance through the ranks and who does not. Whereas an increasingly greater number of students from diverse backgrounds are entering the game by enrolling at higher education institutions, the profile of higher education leaders has changed to a limited extent (American Council on Education, 2017). Because these leaders frequently are the ones making the rules, those who are new to the game can face considerable obstacles to reaching their goal.

Note: We would like to thank the participants in this study for providing such rich and candid responses relating to their perceptions and experiences. We hope that we have done you justice. Also, we are grateful to Dr. Theresa Meeks for sharing her perspective during the early stages of writing up the results. 
Increasingly more higher education institutions in the United States are mentioning "diversity" in their mission statements (Phillips, 2019). Many institutions have officers and even entire departments devoted to diversity, indicating that it has become somewhat of an imperative in higher education. Nevertheless, there is consensus that higher education institutions should be doing diversity (Ahmed \& Swan, 2006) more effectively. However, it is not clear that there is the necessary willingness and/or ability to do so at many institutions (Carey et al., 2018).

Whereas the benefits of greater diversity for institutions in terms of educational quality and student outcomes have been well-documented (e.g., Rizvi et al., 2019), there seems to be less interest in how more inclusive institutions can benefit people from minoritized groups. The mere presence of individuals with varying perspectives based on their different life experiences and backgrounds is insufficient to generate positive outcomes (van Knippenberg \& Schippers, 2007). Scholars (e.g., Puritty et al., 2017; Templeton et al., 2016) have called on researchers in the areas of diversity and inclusion to move beyond an examination of numbers to explorations of the perceptions and experiences of people from minoritized groups. Although higher education surveys and reports often focus mainly on gender and race (Garvey, et al., 2019), it is crucial to include voices from all groups (Harris et al., 2015), especially those who historically have been excluded. According to standpoint theorists (e.g., Collins, 1997; Smith, 1997), people from minoritized groups have the most accurate knowledge of the origins, scope, and indicators of injustice. Further, unlike individuals with more privileged identities, they recognize that inequality is a product of social conditions, rather than an inevitability. Consequently, research on diversity and inclusion and associated initiatives in higher education, including this work, should position individuals from minoritized groups as the experts of both their experiences and the ways in which higher education can make meaningful progress towards greater diversity and inclusion. This work was founded upon the assumption that individuals in groups who share common placement in hierarchical power relations also share experiences. Those experiences are interpreted similarly by group members and, therefore, should be at least as important as issues of individual agency or diversity.

\section{Method}

The purpose of this study was to examine how "diversity" and "inclusion" and related initiatives are interpreted, understood, experienced, created, and/or constituted (Astalin, 2013) at higher education institutions from the perspectives of faculty, staff, and administrators who are also members of minoritized groups. Diversity- and inclusion-related initiatives were defined as efforts specifically designed to increase the representation and integration of people with minoritized identities, rather than focusing on one particular group. Doing so allowed for a broader examination of perceptions and experiences of individuals across the institution and a recognition of intersecting systems of (dis)advantage. Given the study's purpose, a qualitative methodology and thematic analysis were used.

\section{Participants}

Thirty-three faculty, staff, and administrators who both (a) worked at a higher educational institution in the United States and (b) reported being a member of a minoritized group in terms of their sex, gender, race, sexual orientation, age, ability, religion, social class, and/or other characteristic participated in this study (see Table 1). Consistent with the breakdowns at higher education institutions, faculty were represented to the greatest extent $(n=21)$, whereas administrators were represented to the least extent $(n=5)$. On average, participants had worked in higher education for $12.5(\mathrm{SD}=8.85)$ years. Almost all participants reported being a member of more than one minoritized group, with the greatest number reporting identities relating to their sex $(n=30)$ and gender $(n=30)$ and the fewest reporting identities relating to their ability $(n=1)$. Although they had the opportunity to write in the specific groups (e.g., woman, bisexual) with which they identify, few did so. 
Table 1: Description of Participants

\begin{tabular}{|c|c|c|c|c|}
\hline Participant & Position & Institution Type & $\begin{array}{l}\text { Years in } \\
\text { Higher Ed }\end{array}$ & Group Membership \\
\hline 1 & Administrator & Public & 22 & $\mathrm{~S}, \mathrm{G}, \mathrm{A}$ \\
\hline 2 & Administrator & Private & 27 & $\mathrm{~S}, \mathrm{G}, \mathrm{R}$ \\
\hline 3 & Administrator & Private, Not-for-profit & 4 & $\mathrm{G}, \mathrm{R}$ \\
\hline 4 & Administrator & $\begin{array}{l}\text { Private, For-profit, } \\
\text { Completely online }\end{array}$ & 12 & S, A \\
\hline 5 & Administrator & Public & 22 & $\mathrm{~S}, \mathrm{G}, \mathrm{A}$ \\
\hline 6 & Faculty & Public & 6 & $\mathrm{~S}, \mathrm{G}, \mathrm{A}$ \\
\hline 7 & Faculty & Public & 3 & $\mathrm{~S}, \mathrm{G}, \mathrm{R}, \mathrm{SC}$ \\
\hline 8 & Faculty & Public & 30 & $\mathrm{~S}, \mathrm{RE}$ \\
\hline 9 & Faculty & Public & 18 & $\mathrm{~S}, \mathrm{G}, \mathrm{O}$ \\
\hline 10 & Faculty & Public, Brick-and-mortar & 8 & $\mathrm{~S}, \mathrm{G}, \mathrm{R}$ \\
\hline 11 & Faculty & Public, Brick-and-mortar & 8 & $\mathrm{~S}, \mathrm{G}$ \\
\hline 12 & Faculty & $\begin{array}{c}\text { Public, Not-for-profit, } \\
\text { Brick-and-mortar } \\
\end{array}$ & 2 & $\mathrm{~S}, \mathrm{G}, \mathrm{AB}$ \\
\hline 13 & Faculty & Private & 13 & $\mathrm{G}, \mathrm{R}$ \\
\hline 14 & Faculty & Private & 22 & $\mathrm{~S}, \mathrm{G}, \mathrm{R}, \mathrm{A}, \mathrm{SC}$ \\
\hline 15 & Faculty & Private & 7 & $\mathrm{~S}, \mathrm{G}$ \\
\hline 16 & Faculty & Private, Brick-and-mortar & 14 & $\mathrm{~S}, \mathrm{G}, \mathrm{SO}, \mathrm{A}$ \\
\hline 17 & Faculty & $\begin{array}{c}\text { Private, Not-for-profit, } \\
\text { Brick-and-mortar }\end{array}$ & 16 & $\mathrm{~S}, \mathrm{G}, \mathrm{R}, \mathrm{RE}$ \\
\hline 18 & Faculty & $\begin{array}{l}\text { Private, Not-for-profit, } \\
\text { Brick-and-mortar }\end{array}$ & 9 & $\mathrm{~S}, \mathrm{G}, \mathrm{R}$ \\
\hline 19 & Faculty & $\begin{array}{c}\text { Private, Not-for-profit, } \\
\text { Brick-and-mortar }\end{array}$ & 1 & $\mathrm{R}$ \\
\hline 20 & Faculty & $\begin{array}{l}\text { Private, For-profit, } \\
\text { Completely online }\end{array}$ & 15 & $\mathrm{~S}, \mathrm{G}, \mathrm{SO}$ \\
\hline 21 & Faculty & $\begin{array}{l}\text { Private, For-profit, } \\
\text { Completely online }\end{array}$ & 14 & $\mathrm{R}, \mathrm{A}$ \\
\hline 22 & Faculty & For-profit & 10 & $\mathrm{G}, \mathrm{R}$ \\
\hline 23 & Faculty & $\begin{array}{l}\text { Private, Not-for-profit, } \\
\text { Brick-and-mortar }\end{array}$ & 12 & $\mathrm{~S}, \mathrm{G}, \mathrm{SO}$ \\
\hline 24 & Faculty & Private & 28 & $\mathrm{~S}, \mathrm{G}, \mathrm{SO}$ \\
\hline 25 & Faculty & Public & 22 & $\mathrm{~S}, \mathrm{G}, \mathrm{R}, \mathrm{SO}, \mathrm{SC}$ \\
\hline 26 & Faculty & Public, Not-for-profit & 4.5 & $\mathrm{~S}, \mathrm{G}$ \\
\hline 27 & Staff & Public, Brick-and-mortar & 3 & $\mathrm{R}, \mathrm{RE}$ \\
\hline 28 & Staff & $\begin{array}{c}\text { Public, Not-for-profit, } \\
\text { Brick-and-mortar }\end{array}$ & 1 & $\mathrm{~S}, \mathrm{G}, \mathrm{SO}, \mathrm{RE}, \mathrm{SC}$ \\
\hline 29 & Staff & $\begin{array}{l}\text { Public, Not-for-profit, } \\
\text { Brick-and-mortar }\end{array}$ & 3 & $\mathrm{~S}, \mathrm{G}, \mathrm{SO}, \mathrm{A}$ \\
\hline 30 & Staff & $\begin{array}{l}\text { Public, For-profit, } \\
\text { Brick-and-mortar }\end{array}$ & 5 & $\mathrm{~S}, \mathrm{G}, \mathrm{R}, \mathrm{SC}, \mathrm{O}$ \\
\hline 31 & Staff & Private & 30 & $\mathrm{~S}, \mathrm{G}, \mathrm{RE}$ \\
\hline 32 & Staff & $\begin{array}{l}\text { Private, Not-for-profit, } \\
\text { Brick-and-mortar }\end{array}$ & 5 & $\mathrm{~S}, \mathrm{RE}$ \\
\hline 33 & Staff & Public & 14 & $\mathrm{~S}, \mathrm{G}, \mathrm{R}, \mathrm{A}, \mathrm{SC}$ \\
\hline
\end{tabular}

Note. Sex $=\mathrm{S}$, gender $=\mathrm{G}$, race $=\mathrm{R}$, sexual orientation $=\mathrm{SO}$, age $=\mathrm{A}$, ability $=\mathrm{AB}$, religion $=\mathrm{RE}$, social class $=\mathrm{SC}$, and other characteristic $=\mathrm{O}$. 


\section{Instrument}

A review of the previously cited literature on diversity, inclusion, equity, and access and associated initiatives in higher education informed the development of a 15-item anonymous electronic questionnaire. Participants were asked to provide information regarding to what degree their institutions are diverse; the extent to which they feel involved, respected, and connected at their institutions; what efforts and associated outcomes are occurring to promote diversity and inclusion at their institutions; and what recommendations they have for promoting diversity and inclusion in higher education.

\section{Procedure}

An invitation to participate in this study was (1) sent via LinkedIn InMail and (2) posted in relevant online forums on social media sites, including Facebook, Twitter, and LinkedIn. Participants were also encouraged to share the information with anyone whom they thought might be interested in taking part in the study. An electronic survey strategy was selected because it combines the advantages of interviews (e.g., prompts and branching) and pen-and-paper questionnaires (e.g., standardization and anonymity) (Kiesler \& Sproull, 1986). The questions were designed to elicit open and honest descriptions of participants' perceptions and experiences. To minimize any potential harm to participants, limited demographic data were collected to ensure the inclusion criteria were met. No identifying information was collected. Nearly all items had an open-ended response format, and no item had a forced response.

Thematic analysis (Braun \& Clarke, 2006) was used to identify patterns across responses. First, two researchers read the responses several times to familiarize themselves with the data. Using MAXQDA, they then independently coded the earliest responses before engaging in discussion. Next, they coded the remaining data based on their shared understanding of the patterns across responses. Once saturation was reached, they came together again for discussion to ensure alignment of codes and categories. A third researcher was then brought in to refine interpretations (Barbour, 2001). The coding scheme was refined until all researchers were satisfied with the level of agreement, as recommended by Campbell et al. (2013). Finally, a theme was generated from the categories, and the primary investigator re-analyzed all the data to ensure fit.

As was the case with the participants, the researchers' lived experiences impacted their views of the world as well as their research decisions and interpretations. It was important for them to address how their identities influenced the research (Muhammad et al., 2015). They recognized that white, highly educated, financially stable women enjoy greater advantages than individuals who face intersecting systems of (dis)advantage in association with these and other identities. Recognizing their positions as outsider and insider researchers and the ways that they might impact the research design and interpretations, the researchers practiced reflexivity, collected data anonymously, and reviewed works authored by members of minoritized groups extensively (Greene, 2014; Muhammad et al., 2015) to avoid as much as possible reinforcing harmful hierarchies and social dynamics.

\section{Findings}

Participants frequently described diversity and inclusion efforts at their institutions as superficial at best and/or misleading at worst (e.g., "window dressing" [Faculty 25], "lip service" [e.g., Faculty 16, Faculty 22], and "just a tagline" [Staff 30]). Therefore, the overall theme was "talk[ing] a good game" (Faculty 23). Those who were aware of institutional efforts to promote diversity and inclusion, which almost exclusively included task forces ("of course, because Universities create task forces for everything" [Staff 30]), meetings, committees, and trainings, generally described them as narrowly focused. For the most part, participants did not seem to think that these efforts extended beyond raising awareness and merely stating a commitment to diversity and inclusion. 
Contradictory to this stated commitment, participants reported that initiatives to promote diversity at their institutions were lacking in measurable, observable outcomes. According to Staff 27, "we have departments and initiatives that specifically cater to the marginalized and disenfranchised sector of our student population. I don't think our anticipated outcomes match the effort." Administrator 4 stated, at their institution, "the emphasis seems to be on checking boxes now....I do not know that we have recruited, hired, retained, or promoted many women or people of color. It hasn't been an obvious shift.” Administrator 5 expressed frustration about the lack of progress at their institution, as "nothing really changes. What galls me most is that until recently (things are slowly changing), the institution used to brag about its diversity efforts, not one of which made any difference (as far as I could see)." According to Staff 27, "our mission statement speaks to the need for diversity. I have heard and witnessed a contradiction to this position."

Several reported dynamics seem to be associated with participants' perceptions that diversity and inclusion efforts at their institutions are mostly talk with little to no meaningful action, as represented in the following categories: (a) tunnel vision (narrow view of diversity and inclusion that ignores individuals and groups in the periphery), (b) playing by others' rules (lack of representation among and legitimation from those in power), (c) uneven playing field (feeling of powerlessness), (d) relegated to the sidelines (marginalization), (e) doing the heavy lifting (completing much of the diversity and inclusion work themselves), and (f) taking a time out (distancing or preparing to leave the institution).

\section{Tunnel Vision}

Participants generally reported that any diversity and inclusion efforts at their institutions have an excessively limited focus, usually on one particular area (e.g., hiring practices) or role (e.g., faculty, staff, students) or the recruitment of individuals from a specific group (e.g., women, Black individuals). Such a narrow view reportedly resulted in the exclusion of those from other minoritized groups. Regarding their institution, Administrator 4 shared:

I do not believe that it is diverse....I have seen the data that show that white men are represented to the greatest extent. However, we do not collect or report data on other factors....We need to view diversity more broadly to include other factors in addition to race and sex.

Participants tended to emphasize this narrow view of diversity and inclusion when it centered around other minoritized groups of which they were not a member. For example, several faculty who did not report being a member of a minoritized group in terms of their race shared that their institution only considers diversity in terms of hue. These participants overwhelmingly reported only sex and/or gender (and age, in a few cases) among the minoritized groups. Faculty 26 stated that "our definition of diversity seems to be skin color." Faculty 6 shared a similar perspective: "Diversity is more so addressed as race/ethnicity rather than sex/gender. I don't feel that many steps are taken to promote gender/sex diversity.” Likewise, Administrator 5 stated:

Here, it always reduces to a Black/White issue or that there are many international faculty and grad students serve as some sort of proxy for diversity (without acknowledging that international students/faculty are majority in their countries of origin). Very little acknowledgement that there is an absence of domestic diversity.

Although most participants identified as a member of more than one minoritized group, they tended to focus primarily on their experience in association with one (most commonly relating to their sex and/or gender). Nevertheless, a few participants did mention the impact of intersecting systems of (dis)advantage. Faculty 16 shared, "even starting my 10th year, it is still hard to be taken seriously as a woman, particularly one who is younger." Faculty 15 explained how they attempt to navigate barriers, stating that "as a working mom, I have been asked about how I would manage this job with children. I feel like I have to pretend that I don't have children so that being a woman doesn't hurt me." 
Several participants reported that institutional efforts to promote diversity and inclusion often focused heavily or even exclusively on students, neglecting other stakeholders. Staff 29 shared, "sometimes it feels like they ["upper management"] only have to worry about diversity and inclusion for students, but not in themselves or higher up. I also think many times the university is very reactionary as opposed to proactive." Consequently, participants, particularly faculty (e.g., Faculty 10, 11, and 21), frequently highlighted a mismatch between the students served by their institutions and the faculty and staff who work with them. Staff 27 reported, "I work for an institution that caters to the [racial/ethnic group] population, yet we are severely underrepresented in all areas (administration/faculty/staff)."

In addition, many participants described institutional efforts to promote diversity and inclusion as occurring independently, yet simultaneously. Faculty 23 stated that "we have all of these organizations and activities that draw specific groups together, but do not promote interaction amongst the groups." Moreover, several participants discussed the existence of committees focusing on first-order changes (e.g., Faculty 22 mentioned a committee to discuss the potential removal of statues on campus in an attempt to address racism) that do not disrupt or dismantle the larger systems of (dis)advantage that created and maintain the lack of diversity and inclusion at higher education institutions.

\section{Playing by Others' Rules}

Participants seemed to notice differences between the individuals who are making the decisions and those who primarily are impacted by them at their institutions. However, they offered divergent responses regarding the extent to which they believed that their membership in a minoritized group impacted their experiences at their institutions. A few of them reported that it did not impact them or impacted them positively, emphasizing an embracing of or focus on diversity and inclusion at an institutional level. According to Faculty 8, who reported being a member of a minoritized group in terms of sex and religion, "it hasn't [impacted my experience]! My college embraces diversity and inclusion.... If anything, white men are a dying breed.... Good luck getting a position, dude!" Administrator 3, who reported being a member of a minoritized group in terms of gender and race, was the sole participant to report only a positive impact on their experience, stating, "my institution is deeply focused on equity and inclusion, so it has been advantageous for me as a member of a marginalized group."

However, most participants described negative consequences (e.g., "it has limited my career" [Administrator 1]). These reports often surrounded the participant's sex and/or gender. Faculty 9 shared, "I've seen the impact gender and sex have on my institution. It's very much a 'boys club." Other participants emphasized that they are expected to follow a different set of rules and/or exceed different standards than others with more privileged identities. Faculty 11 explained, "I've been told that people often talk behind my back because I 'do too much' and I 'say what I think.' Women are generally expected to be quiet." Faculty 9 shared, "I'm often seen as 'the diversity lady,' and my topics aren't legitimized by my colleagues." A few participants also mentioned that they do not feel as though their personal relationships are legitimated, putting them in the position of having to decide whether to provide clarification or "out" themselves:

With every interaction, there is a possibility that I may be assumed gay or assumed straight. My students and I engage in conversation and not just about classes. Students will ask what my husband does for a living or what my husband thinks about something else. I will correct them and tell them that my wife is a [profession] and that she loves blah, blah, blah. Similar interactions come up with colleagues. (Faculty 23)

In addition to facing delegitimation, some participants described experiences that might be considered as dehumanizing. Staff 27 shared that they feel "disrespected by those who avoid me." Staff 30 seemed to suggest that theses dynamics in the workplace are replicating those that occur in other public spaces. Regarding the extent to which they felt respected at their institution, they stated that it is: 
likely based on how respected I usually feel in any given space. People feel free to not address me by my name, while addressing others by theirs. People walk past and do not share a greeting. People hang around my workspace and prop their personal items up on it when they have their own office or space.

Several participants reported that their legitimacy and humanity often are recognized only when they can be beneficial to someone else. Faculty 17 shared, "I think people respect others to the extent that they can get what they want from them at my workplace, or at least some seem to be this way." According to this same faculty member, when they have attempted to address issues relating to diversity and inclusion, their perceptions and experiences often are not treated as valid:

In some serious situations, I feel that my concerns have been overlooked and even mitigated by my superiors. Words, such as "attitude" and "freaking out," have been used to describe my behavior when approaching supervisors with serious issues and concerns regarding pay and job responsibilities.

Faculty 14, who identified as being a member of a minoritized group in terms of their sex, gender, race, age, and social class, reportedly noticed improvements upon earning an increase in rank: "Since becoming a full professor, I have sensed more respect and have appeared in several news stories. My opinion and expertise are sought out frequently for market research, etc.”

Several participants reported that individuals who are higher up in the organizational hierarchy and, therefore, ultimately make decisions typically do not tend to be members of minoritized groups. According to Faculty 16, at their institution, "generally, the higher you climb, the less diverse." Most participants stated that the decision makers at their institutions were overwhelmingly white and male. Faculty 24 shared, "unfortunately, the many positions of power are seemingly dominated by members of the majority groupwhite men. We have yet to have a woman president or a president of color." Administrator 5 explained:

I am a woman in higher ed administration. My current institution has many mid-level administrators who are women, but almost no women are in real positions of power.... Executive leadership remains woefully dominated by older, white, male, hetero, cis. That sends a very loud message that the institution does not seem to hear.

At the same time, numerous participants reported that members of minoritized groups often hold relatively low-ranking positions at their institutions. According to Faculty 25, "Many of the staff of color are housekeepers, maintenance workers, or dining hall [workers] (in other words, low paid).” Similarly, Administrator 5 stated that "on the staff side, almost all of the people of color are in low-level positions...." Staff 30 shared a similar perspective:

Higher education institutions are "diverse" mainly to people who are not themselves "diverse." Let my institution tell it, they are diverse. And, indeed, they do exhibit higher statistical diversity in the student population than do other universities in our state. However, the diversity drops drastically as you begin to examine professors of rank, subjects of expertise, staff populations, etc.

\section{Uneven Playing Field}

Several participants mentioned feeling as though they are granted less power and/or prestige than others due to their membership in a minoritized group, primarily relating to their sex and/or gender. According to Staff 29, "I have had some students disrespect my authority because I am a woman." Similarly, Faculty 22 stated, "women are paid less, and [their] ideas [are] discounted." Staff 28 also shared how they were impacted financially: 
I know quantifiably that I am being paid significantly less than the starting pay of my predecessor, who is male. I was also offered the job at significantly lower ( $\$ 5 \mathrm{k}$ lower) [pay] than the advertised range.... I was underbid for the job, despite having a master's degree.

Given this situation, Faculty 13, who reported being a member of a minoritized group in terms of gender and race, explained, "I believe that I do have to work harder than my colleagues to be recognized." Participants sometimes linked these reports to their position within the organizational structure. In general, negative perceptions and feelings of disrespect within their departments and across their institutions were reported more commonly by staff than faculty; administrators shared such reports least frequently. Staff 31 described "the faculty-staff divide (I'm staff and feel disrespected by faculty)." Likewise, Faculty 7 shared, "for the most part, my department colleagues respect me. But I have faced discrimination across campus by some administrators."

Although some version of the term(s) "diversity" and/or "inclusion" reportedly often was included in their institutions' strategic plans and mission statements, in practice, several participants reported that diversity and inclusion efforts are low in priority at their institutions. They explained that there are limited resources devoted to and incentives tied to these initiatives in comparison to other initiatives. Faculty 25 explained, "We have a new Vice President of Diversity, Equity, and Inclusion. But she is the only vice president with no staff and no budget...." Staff 30 argued that higher education institutions must:

make it [diversity/inclusion] a priority and stop just using it as a tagline. D/I has for too long been a nice optional thing to do. It is not "nice." It is expected. It is not optional. It is required. It's expected that an institution of higher learning operate with higher-order ideals and, indeed, seek to meet those ideals for the betterment of society.

Faculty 23 described the only instance of an institutional leader's publicly showing support for minoritized groups by sending messages condemning violence towards LGBTQ+ individuals and protesters of white supremacy as well as welcoming undocumented students and students who have been displaced from their home countries. Staff 30 described a faculty member's publicly challenging institutional leaders on the issue:

During one of the university presidential forums, a professor made the example that if the issues were about research we wouldn't be told "to wait" and that "change takes time." Money, support, and a plan would be in place to make the change happen. Since then, I've seen almost a 180 in the types of programs offered around diversity and inclusion. Grants for adding diversity/inclusion components to courses have been created. There is a task force for D/I...D/I programs, student events, etc., have all increased.

Nevertheless, several participants reported that they did not feel comfortable speaking up. Describing their institution as "a very don't-rock-the-boat type of place," Administrator 5 shared:

I am very involved [in my institution]. I lead a unit that is responsible across multiple colleges and campuses. I feel less powerful when it comes to speaking truth to power, although there are some allies who seem to get it.... There is a weird culture here that expects 100\% loyalty.

\section{Relegated to the Sidelines}

Based on participants' responses, it seems that few of their institutions are taking meaningful steps to leverage what diversity does exist to achieve greater integration (and, therefore, the associated benefits of diversity). Administrator 3 shared, "I am a member of the diversity committee and sit in on all faculty hiring; issues of diversity permeate both processes. Inclusion is not an explicit focus." Many participants frequently stated that they felt "marginalized" at their institutions. Consequently, some of them reported a complete lack of 
awareness of efforts at their institutions to promote diversity and inclusion. For Faculty 16, their feeling of marginalization reportedly was due to a mismatch between the university's priorities and their own: "I work for a religiously affiliated school and am not religious personally, so that is difficult for me." Staff 30 described a similar mismatch, but also mentioned departmental siloing:

I am unfortunately not very "involved" with my institution. Part of that is the fact that it is so large, and I enjoy having a personal life that doesn't merge with my institution's brand. The other part is because my department is siloed and does not work to collaborate with others outside of its general area of expertise.

Likewise, Faculty 12 stated that "trainings are great, but [there are] not a lot of other interactions with outside departments.” Within their own departments, participants reported relatively better situations.

Not all staff shared this experience of marginalization. Staff 27, who reported being a member of a minoritized group in terms of race and religion, reported a high degree of integration within their institution because "[m]y position allows for very personalized conversations with all stakeholders on campus" as well as "many opportunities to be part of meetings and conversations that are privy to few people on campus." Similarly, most faculty and all administrators reported a relatively higher level of integration and access within their institutions. Faculty 19 explained, "I can converse freely with the president and with the custodian in the same way." Other faculty and administrators explained that their feeling of inclusion was due to their service, extracurricular, and departmental activities (e.g., on one or more committees, as an advisor to a student organization, in a part-time administrative role).

Most frequently, however, participants who reported feeling more integrated primarily attributed it to others' giving them positive feedback and soliciting their opinions and/or recommendations. Faculty 15, who reported being a member of a minoritized group in terms of sex and gender, shared, "I feel respected. Others ask for my opinions and treat me well." On the contrary, participants who shared that they felt marginalized often reported that their opinions and perspectives are rarely solicited and, if they are, are rarely implemented. These individuals also tended to report multiple markers of marginalization. Staff 29 shared, "I know a bit about what is going on in important decision-making circles, but my input is not particularly asked for or considered." Staff 33 explained, "I do not feel respected [at my institution] at all. I am invited to meetings, but my ideas are not considered at all." Some participants attempted to provide additional explanations for why they do not feel included. Administrator 4 stated, "I am not always in the discussions in which I should be. It could be because of my sex and/or age (I'm younger), but it might also be due to my role." Although Staff 29 reported a similar experience, they did not believe that their experience was related to their membership in a minoritized group:

I know I am a valued employee, but again, my opinion on student affairs is not really considered by the Dean of my college or anything like that. I feel like that happens a lot in large organizations. The managers make decisions that affect the frontline workers without asking for their perspective on changes. I do not think this has to do with my membership in a historically marginalized group. I do think my perspective should be included more.

\section{Doing the Heavy Lifting}

Many participants stated that they were doing work themselves to promote diversity and inclusion, both in their primary roles and beyond. Administrators focused on activities, such as campus trainings, faculty recruitment initiatives, and committee work, all of which participants generally described as having minimal to no impact. Faculty overwhelmingly reported that their work towards diversity and inclusion occurred in their teaching/instruction (as opposed to research, supervision, and/or service). Nevertheless, they did not seem to think that it necessarily required it. Moreover, faculty seemed to focus their efforts almost exclusively 
on student impact. Several of them mentioned efforts to improve student outcomes, such as "promoting completion" (Faculty 22) and the "retention of undergraduate students from under-represented groups" (Faculty 16), as steps that they are taking to enhance diversity and inclusion. In a parallel process to what they described at the institutional level, there was limited explanation regarding how exactly faculty focus on these areas in their teaching and what specific steps that they take to measure and achieve these student outcomes.

Unless their job descriptions included a direct focus on diversity and/or inclusion, staff seemingly did not see a connection between a focus on diversity/inclusion and their job duties. Others apparently felt overwhelmed or unsupported in moving beyond awareness raising to taking action to promote diversity and inclusion. Faculty 24, who reported being a member of a minoritized group in terms of sex, gender, and sexual orientation (but, notably, not race), stated that they "feel strongly about supporting diversity and inclusion initiatives. However, I am just one staff person pretty low on the totem pole."

In addition to their primary roles, several respondents stated that they were expected to do additional work above and beyond their roles associated with their membership in a minoritized group, despite the reported lack of legitimation. Faculty 7 discussed the associated additional burden on their time and emotional wellbeing:

I am placed on committees to fulfil a diversity quota, where I am asked to do more than my colleagues because of my diverse background. In addition, many students come to me over my colleagues because they identify with me, but that too taxes my time (and emotions) disproportionally more than my colleagues'.

Similarly, Faculty 25 shared, "I get many more student questions and stories than the white men who have offices near me do." In addition, Faculty 14 stated, "I chair the diversity committee; I am frequently asked as a POC [person of color] to assist with diversity programming, and I advocate for students/faculty with disabilities and do research on disability and minority rights." This faculty member shared that this additional work has impacted their experiences "[a] lot both in terms of the labor to stage diversity programming and as a mentor for people from underrepresented groups."

Some participants expressed a personal interest in taking the initiative to promote diversity and inclusion on their own. Faculty 24 stated:

I feel strongly about being as educated as I can about the issues surrounding diversity and inclusion in my department and at my university. However, it is more so something I take upon myself to learn and put into practice, not necessarily something that comes from the top down.

Similarly, Staff 29 shared:

I have had to seek out spaces to get more involved. It has not been encouraged by my supervisors or anyone higher up, but they do allow me to participate in what I want to do. They haven't tried to prevent me from participating in trainings and are open to discussing what I learn. My boss has never said anything about the whole office needing to attend diversity and inclusion trainings or anything like that. It is not on his radar.

Similarly, Administrator 4 wrote that they focus on diversity and inclusion in their position to "a limited extent," adding:

I have to make it a priority and do work on my own to promote diversity/inclusion. There are no mentors or officers at my institution of whom I am aware. I have asked for mentoring in these areas, but no one seems to know to whom I should go. 


\section{Taking a Time Out}

Participants' reactions to their experiences at their institutions as members of minoritized groups seemed to vary along a continuum. Many of them apparently were grappling with mixed emotions and/or divergence between their feelings/perceptions and experiences/observations, which often took the form of "yes, but." Many times, they would make a positive statement (e.g., they feel included at their institution), then immediately follow it up with a contradictory statement (e.g., they are not involved in decision making). However, other participants clearly had strong negative feelings. Faculty 6 wrote, "I... hold negative feelings based on my experiences." Staff 33 explained that "I am not happy working in an environment that I am marginalized and disrespected." Although a few participants stated that they had noticed an improvement in the degree of diversity and inclusion at their institutions, they also reported experiencing overt discrimination. Emphasizing "highly defined" gender roles at their institution, Faculty 11 explained, "Although it has gotten a little better since I've been there, there is still evidence of sexism." Faculty 25 shared, "I have heard a handful of racist and sexist comments. Heteronormativity is relatively pervasive.” Also, Faculty 17 stated, "I think there is prejudice and discrimination against me from a few colleagues as well as a handful of students."

As a result, some participants reportedly are making attempts to distance themselves psychologically and/or physically from their institutions. Faculty 21 shared, "I'm not involved [in the institution], given I maintain a distance.” According to Staff 28, "I don't really feel connected at all. It's just a job.” Similarly, Faculty 26 shared, "My new mantra is 'I just work here." Faculty 17 described how this distancing occurred over time: "I was very involved my first six years. I have become disillusioned and taken myself off all committees for this year. I will be on sabbatical next year." Administrator 5 shared, “I honestly can't wait to get an opportunity to get out of here! It is stifling." Likewise, Staff 30 stated:

Based on my experiences here, I am not tethered to staying with them [their institution]. I will always be fond of them, but will take that fondness with me as I move forward to another place of work soon.

Although nearly all participants discussed efforts at their institutions to recruit faculty and staff from minoritized groups, not one of them described efforts to support these individuals after they are hired. Several participants mentioned difficulties at their institutions in retaining faculty and staff from minoritized groups. Faculty 14 stated, "We have a lot of turnover among faculty as well and recently lost our first tenured professor who is African-American."

\section{Discussion}

Although there might appear to be more players in the higher education game, some are only allowed to participate if they play by the existing rules, which continue to be designed by and for those with privileged identities. Others, especially those who challenge or attempt to change the rules, often remain on the sidelines. As a result, not everyone has an equal opportunity of winning. The overall theme of "talk[ing] a good game" aligns closely with Ahmed's (2012) notion of "performance culture," where doing well in terms of diversity and inclusion in higher education involves creating "the right kind of appearances" (p. 84). Despite their institutions' stated commitment to diversity, participants described disjointed efforts to promote diversity and inclusion. Such efforts in the absence of systemic change can backfire and increase behaviors that they are intended to curb (e.g., Duguid \& Thomas-Hunt, 2015).

Instead of being part of a cohesive and consistent plan of change, the efforts described by the participants seemingly amount to little more than box-checking exercises (Lee, 2013). They apparently were designed to increase the number of individuals who appear to represent movement away from institutionalized patriarchy (Cannella \& Perez, 2012) and white supremacy (Ladson-Billings \& Tate, 1995), specifically women and Black 
faculty, staff, administrators, and/or students. Such dichotomous thinking neglects the notions that sex and gender exist on a continuum and can be fluid as well as that individuals can be both non-male/-masculine and non-white.

For the most part, the faculty, staff, and administrators in this study described the diversity and inclusion initiatives at their institutions as excessively narrowly focused. Few participants discussed diversity broadly using an intersectional lens (Crenshaw, 1991), nor were there any reports of efforts to increase representation of individuals from groups with less visible characteristics. In a parallel process to what reportedly was occurring at their institutions, these faculty, staff, and administrators tended to understand diversity and inclusion in terms of the extent to which people like them had (dis)advantages. A small number even engaged in behaviors that members of other minoritized groups might perceive as insensitive (e.g., a faculty member who did not report being a member of a minoritized racial/ethnic group used the phrase "low on the totem pole"). Therefore, it seems that this narrow focus and perpetuation of the status quo occurred at the institutional and individual levels, especially among individuals whose only marker of marginalization related to their sex and/or gender (and age, in a few cases).

By design, diversity and inclusion initiatives should challenge and transform traditional practices and arrangements to make higher education more equitable and open to alternative perspectives (Hirabayashi, 1997). Only then can the benefits of diversity and inclusion to individuals from minoritized groups and institutions be realized. Making a meaningful impact in these areas requires acknowledging that structural bias and social justice impact academics and their work (Puritty et al., 2017). Nevertheless, the foci of the diversity and inclusion initiatives described by the participants in this study did not appear to be on secondorder (systemic) change (Levy, 1986). Consequently, they have the potential to reproduce and/or block the recognition of inequalities (Ahmed \& Swan, 2006). Rather than working within the system that is in place, working within diversity and creating an inclusive environment must involve everyone's critically analyzing the institution's infrastructure (Templeton et al., 2016). However, many participants in this study stated that people tended not to "rock the boat" by disrupting the status quo at their institutions. They often reported that it was not the norm for them or others to speak truth to power about a lack of diversity and/or inclusion. If they did, their concerns reportedly were invalidated. Participants' institutions apparently place little to no emphasis on the institutional climate resulting from infrastructures that maintain intersecting systems of (dis)advantage (Templeton et al., 2016).

Several participants reported that the dynamics maintaining the status quo within their higher education institutions replicated and/or reinforced those occurring in larger society. However, by focusing on the individual and/or societal factors that contribute to the current lack of diversity and inclusion in higher education, institutions find a reason not to commit to true systemic change (Wynn, 2019). Clark (2011) suggested that higher education institutions that view diversity and inclusion merely as words in the mission statement or a dedicated office tend to experience failure. The participants in this study described no wellfunded diversity and inclusion initiatives aimed at systemic transformation at the institutions where they worked. As a result, according to participants, these efforts at their institutions were ineffective or were associated with only superficial movement in these areas. At these institutions, diversity and inclusion initiatives reportedly were relatively low in priority compared to activities, such as research, as evidenced by the limited resources and incentives associated with them. Yet, leaders at some of these institutions reportedly had bragged about diversity and inclusion efforts and even sought awards for them in some cases. According to Prasad and Mills (1997), with such showcasing of institutional diversity, "pride, celebration, and upbeat performances hide the frustrations, anger, tensions, and disappointment of living with the effects of diversity work" (as cited in Ahmed, 2006, p. 98). In this study, several participants expressed frustration in response, as they believed that little, if any, progress had been made in terms of diversity and inclusion at their institutions. 
According to Clark (2011), those leading the diversity and inclusion charge at higher education institutions "have been relegated to the very elementary, yet exceedingly complex, numbers game: demographics and dollars" (p. 57). Nevertheless, true indicators of the extent to which an institution is successful in these areas should be the perceptions and experiences of individuals from minoritized groups. Moreover, the presentation of institutional data in aggregate form misses important distinctions across groups and areas for improvement, including inequities in compensation, workload, and rank. Despite their expertise in and privileged position to address the injustices faced by members of minoritized groups, the faculty, staff, and administrators in this study seemingly had limited to no say in the development, implementation, evaluation, and improvement of diversity and inclusion initiatives at their institutions. Some of them reportedly were not even informed about such efforts.

Consistent with previous findings (e.g., Betts et al., 2009), participants shared that individuals with privileged identities tended to examine issues related to diversity and inclusion at their institutions (e.g., climate) and offer recommendations for improvement. Despite perhaps the best of intentions, these individuals often have not experienced life and faced intersecting systems of (dis)advantage as a person from one or more minoritized groups. Consequently, many of their recommendations, which often become part of institutional strategic plans, can be based upon a deficit-based perspective and perpetuate the subordination of minoritized groups (Iverson, 2007). Harris et al. (2015) argued terms such as "diversity" and "inclusive excellence" and the efforts associated with them often are "co-opted to promote agendas that maintain the status quo" and uphold privilege (p. 23), rather than serving individuals with minoritized identities, especially racially minoritized ones.

Although many of the faculty, staff, and administrators from minoritized groups in this study were not included in the development and implementation of diversity and inclusion initiatives at their institutions, they reportedly are doing work in these areas. Consistent with the findings of Jimenez et al. (2019), the participants in this study described being expected and/or taking it upon themselves to do much of this work because meaningful action is not coming from leaders. At their institutions, it is the people from minoritized groups who might be bearing most of the responsibility for creating a more diverse and inclusive culture, for example, by incorporating diversity-related content into their course materials and contributing more to service (e.g., answering student questions) than their peers with more privileged identities. Nevertheless, the faculty, staff, and administrators in this study stated that their work in these areas frequently is not legitimated at their institutions. This reportedly was true of both visible labor, such as service and research surrounding diversity and inclusion, and invisible labor, such as mentoring of students from minoritized group(s) and assuming the role of "native informant" (hooks, 1994, p. 44).

Whereas universities reportedly make efforts to recruit faculty and staff from these minoritized groups to mirror the diversity of the student population and larger society more closely, survey respondents reported no efforts to empower and integrate them within participants' institutions. Also, no participant described efforts to hold members of the institution, especially those with more privileged identities, accountable for enhancing diversity and inclusion post-hire. Institutions that talk a good game regarding the level of commitment to diversity that is not reflective of reality to attract individuals from diverse backgrounds, are, essentially, offering a bait and switch (Slay et al., 2019). Whereas many institutions' diversity efforts involve recruitment procedures (Girotti et al., 2015) aimed at increasing the number of so-called "diversity hires" (Rhodes \& Lees, 2017), organized efforts to support and retain these individuals once they are hired and hold everyone accountable for doing diversity and inclusion work are equally important (Piercy et al., 2005). Most participants associated the extent to which their perceptions and experiences were positive or negative with their receiving positive feedback and having their input solicited and acted upon.

Consistent with the findings of numerous studies (e.g., Rankin et al., 2010), a number of participants, as a result of their facing exclusivity and sometimes even hostility, explained that they were taking steps to 
distance themselves from or leave their institutions all together. Turnover and attrition among faculty, staff, and administrators from minoritized groups undermine the efforts to increase diversity and inclusion at higher education institutions (e.g., Moreno et al., 2006). Removing barriers contributing to this so-called "revolving door" would be in their best interest so that the benefits of diversity of perspective and experience can be realized.

\section{Next Steps}

To overcome the barriers to achieving greater diversity and inclusion, we can employ an intentional three-step process informed by the findings of this study and the literature. Using these steps, the perspectives of all stakeholders, including and especially those from minoritized groups, can be solicited and implemented. If possible, widely accepted experts who are also members of minoritized groups should oversee this process. According to the participants, multiple modes of communication (e.g., open-ended surveys, focus groups, autophotography) and anonymity (or confidentiality in the case of data-collection strategies involving face-toface contact) are necessary so that everyone can feel comfortable and safe in sharing their perspectives and experiences. Beyond merely seeking areas of convergence, divergent ways of thinking and doing should be solicited, considered, and acted upon.

\section{Step 1: describe the current state.}

Using the various modes of communication described above, institutions can identify areas of strength and weakness in terms of diversity and inclusion. Institutions should broaden discussions and investigations surrounding diversity to include intersecting systems of (dis)advantage and a focus on perspectives and experiences, rather than only increasing the number of individuals from groups with more visible characteristics (e.g., sex, gender, race) in an attempt to make the institution appear to be diverse. Whereas all stakeholders' input should be solicited and seriously considered, it is critical that their responses be disaggregated so that the perceptions and experiences of members of minoritized groups are not drowned out by those of more privileged groups, who often are greater in number. Whereas members of minoritized groups might be invited to share their perspectives and experiences relating to barriers to diversity and inclusion and how they might be overcome, individuals with privileged identities might be asked to reflect on how they perpetuate the status quo and how they can stop. Although common areas of inequity mentioned by participants in this study included influence, compensation, workload, access to promotion/tenure, and value tied to their work, this step might involve an initial investigation of area(s) of (dis)advantage that are potential opportunities for improvement. Follow-up efforts might involve a closer focus on those specific areas for improvement. At the same time, leaders can present disaggregated institutional data, such as those relating to salary and workload. All of this information combined can serve as a baseline for comparison.

\section{Step 2: define outcomes of interest.}

Once the description of the current state has been shared with all stakeholders, opportunities should be available for disagreements to be worked out with the goal of reaching consensus. The external experts can be leveraged to support these efforts. Next, a similar process as was followed in the first step can be followed to define shared diversity- and inclusion-related outcomes based on the cited strengths and weaknesses. These outcomes might involve expanding upon what is going well and improving upon what is not going well in terms of diversity and inclusion as reflected in the description of the current state. During this step, all institutional actors should consider what a truly diverse and inclusive institution might look like. Instead of focusing narrowly on one or more groups, roles, or areas, these outcomes should be at the system level and surround increasing the institution's openness to other ways of thinking, doing, and being. The defined outcomes must be both measurable and observable. By focusing on achieving these shared outcomes, the ripple effect of privileged groups' perpetuating the subordination of minoritized groups can be acknowledged, and the steps toward meaningful change can begin to occur (Gasman et al., 2015). 


\section{Step 3: develop a plan.}

To move beyond the current state and achieve the shared outcomes of interest, institutions need a purposeful plan to achieve diversity- and inclusion-related outcomes. This plan should involve genuine collaboration at the individual and system levels so that efforts are more than box-checking exercises (Lee, 2013). Members of minoritized groups should drive all stages of these efforts (from conceptualization through continuous improvement); however, they should not be left alone to do this work (Jimenez et al., 2019). It is critical not to overburden these individuals with activities that are invisible and either not valued in tenure and promotion decisions (Cuadraz, 1998) or even devalued (Heckman et al., 2017). Shared responsibility for working towards these outcomes should be included in strategic plans and evaluations, from the faculty/staff/administrator level to the course/program/school level. Mechanisms must be in place so that everyone can know to what extent diversity and inclusion efforts are successful beyond the number of people of each gender and racial group at the institution. Actions tied to and progress over time on each outcome can be tracked and shared with stakeholders, for example, on the institutional research page as well as through other more accessible methods.

\section{Limitations}

In keeping the responses anonymous, we were not able to ask probing or follow-up questions or engage in member checking. It was also impossible to observe and note non-verbal cues to further inform data analyses. Moreover, it was not always possible to differentiate among participants' experiences across the myriad diversity- and inclusion-related initiatives and ways that institutions implemented them. A purposefully broad call to participants of minoritized groups was placed instead of focusing on one group (Garvey et al., 2019), which may have limited the breadth of responses from one particular group. However, this method allowed participants to respond freely without judgement or harm to their reputation or employment. Further, it removed potential biases introduced through participants' and researchers' identities.

\section{Conclusion}

If they truly want to elevate their game, higher education institutions should seek to develop actionable steps to become anti-(sexist, racist, homophobic, ageist, ableist, classist, etc.). Attempts to understand diversity and inclusion should be broadened to focus on perspectives and experiences, rather than merely seeking to increase the number of people from minoritized groups with more visible characteristics to make the institution appear diverse. Concrete outcomes that are both measurable and observable must be tied to diversity and inclusion efforts. In addition to convergence, divergent ways of thinking and doing should be solicited, considered, and acted upon. Further, deliberate integration across individuals and departments should be prioritized. Representatives of groups working to improve the situation for specific minoritized groups might partner as part of a larger effort to dismantle systems that perpetuate the status quo, helping to make the institution more inclusive for everyone. For diversity and inclusion initiatives to be successful, they must be at least as high of a priority as activities, such as research. Therefore, they need to be well funded and tied to a plan of institutional change as opposed to being reactionary policies and practices that tend to serve the needs of the institution, rather than the individuals whose situation they are intended to improve. The three-step process described in this work can serve as a guide for stakeholders who are looking to walk the walk when it comes to diversity and inclusion.

\section{References}

Ahmed, S. (2012). On being included: Racism and diversity in institutional life. Duke University Press.

Ahmed, S., \& Swan, E. (2006). Doing diversity. Policy Futures in Education, 4(2), 96-100. 
American Council on Education (ACE). (2017). American college president study 2017. https://www.acenet.edu/news-room/Pages/American-College-President-Study.aspx

Astalin, P. K. (2013). Qualitative research designs: A conceptual framework. International Journal of Social Science and Interdisciplinary Research, 2(1), 118-124.

Barbour, R. S. (2001). Checklists for improving rigour in qualitative research: A case of the tail wagging the $\operatorname{dog}$ ? BMJ, 322(7294), 1115-1117.

Betts, K., Urias, D., \& Betts, K. (2009). Higher educational and shifting U.S. demographics: Need for visible administrative career paths, professional development, succession planning \& commitment to diversity. Academic Leadership: The Online Journal, 7(2). https://scholars.fhsu.edu/alj/vol7/iss2/6

Braun, V., \& Clarke, V. (2006). Using thematic analysis in psychology. Qualitative Research in Psychology, $3(2), 77-101$.

Campbell, J. L. Quincy, C., Osserman, J., \& Pederson, O. K. (2013). Coding in-depth semistructured interviews: Problems of unitization and intercoder reliability and agreement. Sociological Methods \& Research, 42, 294-320.

Cannella, G. S., \& Perez, M. S. (2012). Emboldened patriarchy in higher education: Feminist readings of capitalism, violence, and power. Cultural Studies $\leftrightarrow$ Critical Methodologies, 12(4), 279-286.

Carey, J. M., Carman, K. R., Clayton, K. P., Horiuchi, Y., Htun, M., \& Ortiz, B. (2018). Who wants to hire a more diverse faculty? A conjoint analysis of faculty and student preferences for gender and racial/ethnic diversity. Politics, Groups, and Identities, 1-19. https://doi.org/10.1080/21565503.2018.1491866

Clark, C. (2011). Diversity initiatives in higher education: Just how important is diversity in higher education? Multicultural Education, 18(3), 57-57.

Collins, P. H. (1997). Comment on Hekman's "Truth and method: Feminist standpoint theory revisited": Where's the power? Signs: Journal of Women in Culture and Society, 22(2), 375-381.

Crenshaw, K. (1991). Mapping the margins: Identity politics, intersectionality, and violence against women. Stanford Law Review, 43(6), 1241-1299.

Cuadraz, G. H. (1998). Questions worth asking: Observations from an assistant professor. In Proceedings from keeping our faculties: Addressing recruitment and retention of faculty of color in higher education. Minneapolis, MN: Office of the Vice President and Executive Vice Provost for Faculty and Academic Programs.

Duguid, M. M., \& Thomas-Hunt, M. C. (2015). Condoning stereotyping? How awareness of stereotyping prevalence impacts expression of stereotypes. Journal of Applied Psychology, 100(2), 343-369.

Garvey, J. C., Hart, J., Metcalfe, A. S., \& Fellabaum-Toston, J. (2019). Methodological troubles with gender and sex in higher education survey research. The Review of Higher Education, 43(1), 1-24.

Gasman, M., Abiola, U., \& Travers, C. (2015). Diversity and senior leadership at elite institutions of higher education. Journal of Diversity in Higher Education, 8(1), 1-14.

Girotti, J. A., Park, Y. S., \& Tekian, A. (2015). Ensuring a fair and equitable selection of students to serve society's health care needs. Medical Education, 49(1), 84-92.

Greene, M. J. (2014). On the inside looking in: Methodological insights and challenges in conducting qualitative insider research. The Qualitative Report, 19(29), 1-13.

Harris, J. C., Barone, R. P., \& Davis, L. P. (2015). Who benefits?: A critical race analysis of the (d)evolving language of inclusion in higher education. Thought \& Action, 21-38. https://www.nea.org/assets/docs/TnA-Winter-2015--harrispdf.pdf 
Heckman, D. R., Johnson, S. K., Foo, M., \& Yang, W. (2017). Does diversity-valuing behavior result in diminished performance ratings for non-white and female leaders? Academy of Management Journal, 60(2), 771-797.

Hirabayashi, L. R. (1997). Asian American studies and institutional politics. In T. K. Nakayama \& C. F. Yoshioka (Eds.), Asian Pacific Americans and the U.S. Southwest (pp. 23-38). Arizona State University.

hooks, b. (1994). Teaching to transgress: Education as the practice of freedom. Routledge.

Iverson, S. V. (2007). Camouflaging power and privilege: A critical race analysis of university diversity policies. Educational Administration Quarterly, 43(5), 586-611. https://doi.org/10.1177/0013161X07307794

Jimenez, M. F., Laverty, T. M., Bombaci, S. P., Wilkins, K., Bennett, D. E., \& Pejchar, L. (2019). Minoritized faculty play a disproportionate role in advancing diversity and inclusion. Nature Ecology \& Evolution, 3, 1030-1033.

Kiesler, S., \& Sproull, L. (1986). Response effects in the electronic survey. Public Opinion Quarterly, 50, 402413 .

Ladson-Billings, G., \& Tate, W. F., IV. (1995). Toward a critical race theory of education. Teachers College Record, 97(1), 47-68.

Lee, P. (2013). On checkbox diversity. JCR \& Economic Development, 27(1), 203-216.

Lemon, N. (2018). I am not playing the academic hunger games: Self-awareness and mindful practices in approaching research collaborations. In N. Lemon and S. McDonough (eds.), Mindfulness in the academy: Practices and perspectives from scholars (pp. 129-154). Springer.

Levy, A. (1986). Second-order planned change: Definition and conceptualization. Organizational Dynamics, 15(1), 5-23.

Moreno, J. F., Smith, D. G., Clayton-Pedersen, A. R., Parker, S., \& Teraguchi, D. H. (2006). The revolving door for minoritized minority faculty in higher education: An analysis from the campus diversity initiative. Association of American Colleges \& Universities. Retrieved from https://folio.iupui.edu/bitstream/handle/10244/50/insight Revolving Door.pdf?sequence=1.

Muhammad, M., Wallerstein, N., Sussman, A. L., Avila, M., Belone, L., \& Duran, B. (2015). Reflections on researcher identity and power: The impact of positionality on community based participatory research (CBPR) processes and outcomes. Critical Sociology, 41(7-8), 1045-1063.

Phillips, A. (2019). The quest for diversity in higher education. Pepperdine Policy Review, 11(4). https://digitalcommons.pepperdine.edu/ppr/vol11/iss1/4

Piercy, F., Giddings, V., Allen, K., Dixon, B., Meszaros, P., \& Joest, K. (2005). Improving campus climate to support faculty diversity and retention: A pilot program for new faculty. Innovative Higher Education, 30(1), 53-66.

Prasad, P., \& Mills, A. (1997). From showcase to shadow: Understanding the dilemmas of managing workplace diversity. In P. Prasad, A. Mills, M. Elmes, and A. Prasad (Eds.), Managing the organizational melting pot. SAGE Publications.

Puritty, C., Strickland, L. R., Alia, E., Blonder, B., Klein, E., Kohl, M. T., McGee, E., Quintana, M., Ridley, R. E., Tellman, B., \& Gerber, L. R. (2017). Without inclusion, diversity initiatives may not be enough. Science, 357(6356), 1101-1102. 
Rankin, S. R., Weber, G., Blumenfeld, W., \& Frazer, S. (2010). 2010 state of higher education for lesbian, gay, bisexual, and transgender people. Campus Pride. Retrieved from https://www.campuspride.org/wpcontent/uploads/campuspride2010lgbtreportssummary.pdf.

Rhodes, S. J., \& Lees, N. D. (2017). Dean, chairs, and faculty: A team approach for enhancing faculty diversity. The Department Chair, 27(3), 11-13.

Rizvi, A. A., Naqvi, M. A., \& Batool, M. (2019). Cultural diversity in higher education: Benefits and challenges. International Journal of Innovation in Teaching and Learning (IJITL), 2(2).

Slay, K. E., Reyes, K. A., \& Posselt, J. R. (2019). Bait and switch: Representation, climate, and tensions of diversity work in graduate education. Review of Higher Education, 42, 255-286.

Smith, D. (1997). Comment on Hekman's “Truth and Method: Feminist Standpoint Theory Revisited.” Signs, 22(2), 392-398.

Templeton, E., Love, B., Davis, B. H., Davis. M., Jr. (2016). Illusion of inclusion: University policies that perpetuate exclusion of students of color. Journal Committed to Social Change on Race and Ethnicity, 2(1), 88-115.

van Knippenberg, D., \& Schippers, M. C. (2007). Work group diversity. Annual Review of Psychology, 58, 515-541.

Wynn, A. (2019). Letting companies off the hook: How top executives explain away inequality. https://gendersociety.wordpress.com/2019/10/02/letting-companies-off-the-hook-how-topexecutives-explain-away-inequality/

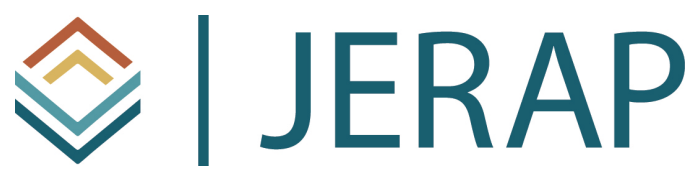

The Journal of Educational Research and Practice is a peerreviewed journal that provides a forum for studies and dialogue about developments and change in the field of education and learning. The journal includes research and related content that examine current relevant educational issues and processes. The aim is to provide readers with knowledge and with strategies to use that knowledge in educational or learning environments. JERAP focuses on education at all levels and in any setting, and includes peer-reviewed research reports, commentaries, book reviews, interviews of prominent individuals, and reports about educational practice. The journal is sponsored by the Richard W. Riley College of Education and Leadership at Walden University, and publication in JERAP is always free to authors and readers. 